\title{
HELIANTHEMUM PUGAE (CISTACEAE), UNA ESPECIE NUEVA DEL CENTRO DE MEXICO'
}

\author{
Graciela Calderon de Rzedowski \\ Instituto de Ecología, Centro Regional del Bajío \\ Apartado Postal 386; 61600 Pátzcuaro, Mich., México
}

\section{RESUMEN}

Se describe Helianthemum pugae Calderón, sp. nov., con base en ejemplares colectados en el $\mathbf{N}$ de Guanajuato y SW de San Luis Potosi. Se asemeja a $H$. patens Hemsl., especie de más amplia distribución en el centro de México y con la cual se le ha encontrado conviviendo.

\section{ABSTRACT}

Helianthemum pugae Calderón, sp. nov., is based on collections made in northern Guanajuato and southwestern San Luis Potosi. It is similar to H. patens Hemsl., species of wider distribution in central Mexico, which was found to grow sympatrically with $H$. pugae.

En el transcurso del trabajo de colecta en relación con el estudio de la familia Cistaceae para la Flora del Bajío y de Regiones Adyacentes, se localizaron plantas pertenecientes al género Helianthemum similares a $H$. patens Hemsl., pero dotadas de un rasgo excepcional para el género, pues son prácticamente glabras. Daoud y Wilbur (1965, p. 287), en su revisión de Helianthemum, al parecer también tuvieron la oportunidad de examinar ejemplares de herbario con estas características, pero las consideraron en forma tentativa como extremo de variación de $H$. patens.

Observaciones recientes realizadas en tres localidades del norte de Guanajuato indican que, si bien las plantas glabras conviven con las pubescentes, los dos tipos se comportan como poblaciones discretas pues, a pesar de florecer al mismo tiempo, casi no se han detectado individuos morfológicamente intermedios. Un examen más minucioso reveló la presencia de discrepancias adicionales entre ambas entidades.

En consecuencia se propone a continuacion:

Helianthemum pugae Calderón, sp. nov. (Fig. 1)

Planta herbacea vel suffruticosa, $10-25 \mathrm{~cm}$ alta, erecta vel aliquot decumbens, vernicosa, aspectu glabro; caules graciles, recti vel flexuosi, saepe profuse ramosi; folia

1 Trabajo realizado con apoyo del Consejo Nacional de Ciencia y Tecnología, del Centro de Investigación y Desarrollo del Estado de Michoacán, de la Secretaría de Educación Pública y del Consejo de Ciencia y Tecnología del Estado de Querétaro. 


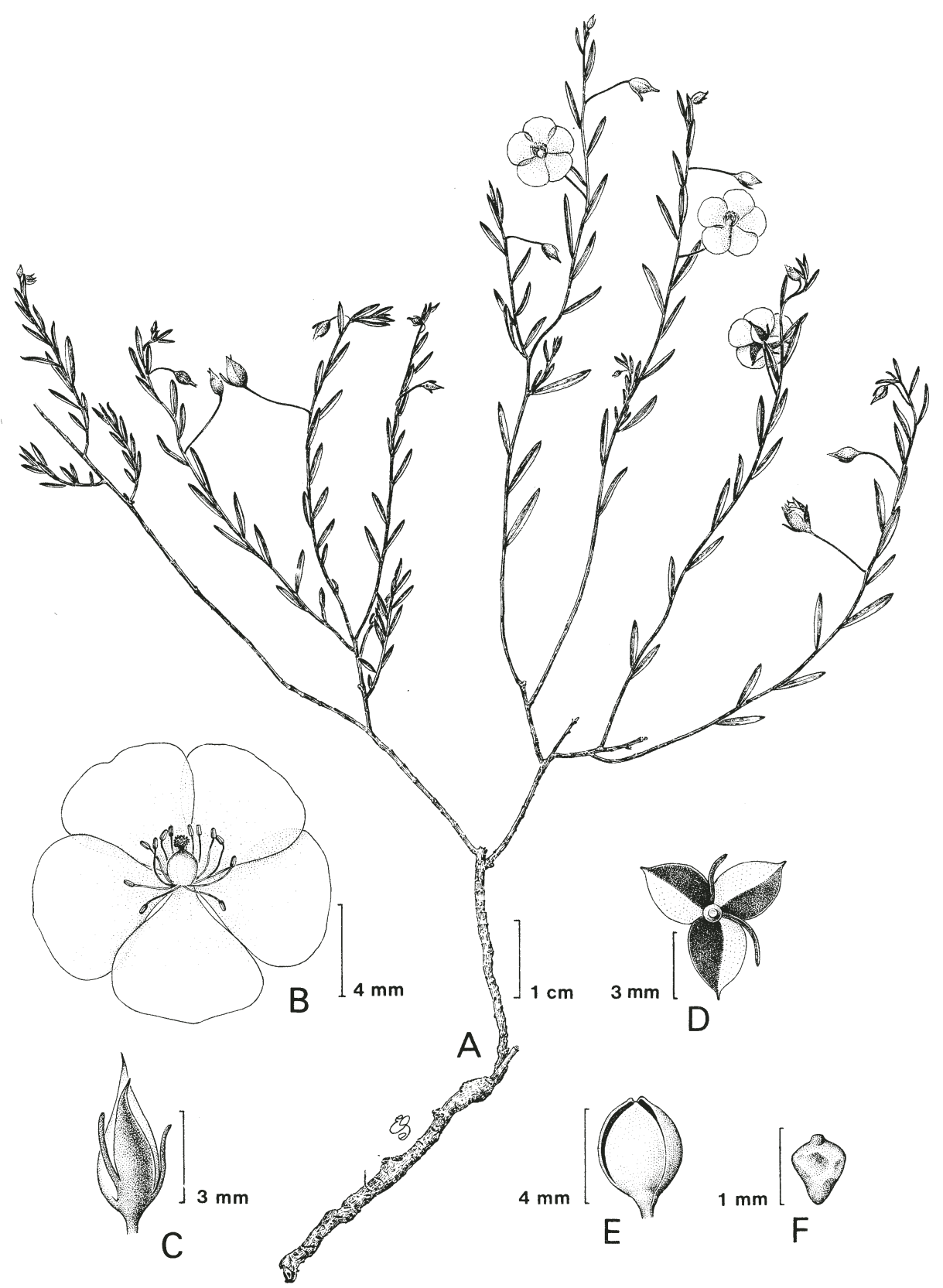

Fig. 1. Helianthemum pugae Calderón. A. Planta entera; B. Flor; C. Botón floral; D. Cáliz visto de abajo; E. Fruto; F. Semilla. 
sessilia, linearia usque ad lanceo-elliptica, 8-10 (15) mm longa, 1-2 (3.5) mm lata, costa infra prominenti; flores pauci, sparsi, omnes chasmogami, pedunculis $\pm 1 \mathrm{~mm}$ longis; alabastrum rubrum, ovoideo-acuminatum, calyx persistens, in fructu paulo accrescens, petala obovata, lutea, $\pm 7 \mathrm{~mm}$ longa, $\pm 6 \mathrm{~mm}$ lata; fructus ovoideus vel subglobosus, \pm 4.5 $\mathrm{mm}$ longus, $\pm 3 \mathrm{~mm}$ latus; semina forma irregulari, trapezoidalia, $\pm 1 \mathrm{~mm}$ longa. Helianthemo patenti Hemsl. simile sed aspectu vernicoso glabroque, foliis angustioribus et alabastris acuminatis 00 discrepans.

Planta herbácea perenne a subfruticosa, erecta o algo decumbente, de 10 a 15 (a 25) $\mathrm{cm}$ de alto, vemicosa, glabra en apariencia (con lente de aumento se aprecia la presencia de pelos simples más bien escasos, muy pequeños, blanquecinos, a veces a modo de papilas, otras veces con una glándula apical diminuta; estos pelos suelen ser más densos en hojas, sépalos y porciones jóvenes de la planta). Raices gruesas y fuertes, a menudo con un alargado sistema de raices secundarias. Tallos delicados, rectos o flexuosos, con frecuencia rojizos, en ocasiones con la corteza exfoliante, sobre todo hacia la parte inferior; ramificación escasa a profusa, saliendo varios a numerosos tallos desde la porción basal. Hojas dispuestas en ángulo muy agudo con respecto al tallo, sésiles, láminas lineares a lanceolado-elípticas, de 8 a 10 (12, rara vez hasta 15) $\mathrm{mm}$ de largo y 1 a 2 (rara vez hasta 3.5) $\mathrm{mm}$ de ancho, con cierta tendencia a colorearse de rojo; ápice agudo; borde liso, en ocasiones algo engrosado; base cuneada a redondeada; nervio medio manifiesto, prominente en el envés, ensanchado y de color más claro en la porción en que se inserta la lámina al tallo. Flores todas casmógamas, esparcidas hacia la parte media y superior del tallo, solitarias, dispuestas en posición altema o subopuestas con respecto a las hojas, pocas abiertas al mismo tiempo en un solo individuo (las demás en etapa de botones y/o frutos), situadas sobre finos pedicelos divergentes de (0.8) 1 (1.5) cm de largo, articulados en la base; botón floral de color rojo, ovoide, acentuadamente acuminado en el ápice, de unos $5 \mathrm{~mm}$ de largo y $2 \mathrm{~mm}$ de ancho; cáliz persistente, un poco acrescente en el fruto, los dos sépalos exteriores lineares, con su porción libre de alrededor de $1.5 \mathrm{~mm}$ de largo, por lo común rojos, los 3 sépalos interiores ampliamente ovados, agudos o acuminados en la punta, de 3 a $4 \mathrm{~mm}$ de largo y de 2 a $3 \mathrm{~mm}$ de ancho, con una mitad de color rojo y la otra amarilla o de color crema; pétalos 5, obovados, con frecuencia truncados hacia el ápice, hasta de unos $7 \mathrm{~mm}$ de largo y $6 \mathrm{~mm}$ de ancho, amarillos; estambres (8) 10 (17), filamentos amarillos y anteras anaranjadas (en vivo); ovario ovoide, estilo corto, estigma penicilado. Fruto ovoide o subgloboso, trivalvado, de 4 a $4.5 \mathrm{~mm}$ de largo y de 3.5 a $4 \mathrm{~mm}$ de ancho, glabro, brillante, verdoso, amarillento o de color café claro. Semillas 15 a 20 (?), de forma irregular, trapezoidales, amarillentas, de alrededor de $1 \mathrm{~mm}$ de largo y $1 \mathrm{~mm}$ de ancho en su parte más amplia, reticuladas, diminutamente papilosas.

TIPO: México, Guanajuato, $10 \mathrm{~km}$ al $\mathrm{S}$ de Ibarra, municipio de Ocampo, sobre la carretera a León, alt. $2250 \mathrm{~m}$, ladera riolítica con vegetación de bosque de Pinus cembroides y pastizal adyacente, 3.VIII.1991, J. Rzedowski 50792 (ENCB, holotipo; duplicados por distribuirse).

Material adicional examinado: México, Guanajuato, $8 \mathrm{~km}$ al ESE de Laguna de 
Guadalupe, municipio de San Felipe, alt. $2350 \mathrm{~m}$, pastizal adyacente al encinar, sobre ladera riolítica, 21.VII.1991, J. Rzedowski 50715 (IEB); $4 \mathrm{~km}$ al SW de La Escondida, municipio de Ocampo, alt. $2100 \mathrm{~m}$, matorral de Dodonaea, próximo al encinar, 11.IX.1991, J. Rzedowski 50929 (IEB). San Luis Potosi, Villa de Arriaga, Cerro del Gallo, alt. 2100 $\mathrm{m}$, base del cerro riolítico, 5.VIII.1954, J. Rzedowski 3361 (ENCB).

Helianthemum pugae se ha encontrado en ambientes subxerofíticos, creciendo en laderas rioliticas, en lugares abiertos, por lo general moderadamente perturbados, a las orillas 0 en claros de encinares o piñonares, ya sea en pastizales o en matorrales secundarios derivados de estos tipos de vegetación, en altitudes entre 2100 y $2350 \mathrm{~m}$.

Aunque hasta la fecha hemos localizado esta planta solamente en el norte de Guanajuato y sur de San Luis Potosí, cabe muy bien la posibilidad de que también exista en hábitats semejantes de áreas adyacentes de los estados de Zacatecas, Jalisco y tal vez en el de Aguascalientes.

Salta a la vista su parecido con $H$. patens en: a) el aspecto general de la planta, b) la presencia de flores isomórficas, todas casmógamas, solitarias, más bien escasas, colocadas sobre pedicelos largos y dispuestos en posición alterna o subopuesta con respecto a las hojas, pero a la vez se distingue perfectamente de la misma en: a) el carácter vernicoso y casi glabro, b) las hojas más angostas (lanceoladas a lineares), c) los botones florales manifiestamente acuminados, d) el porte por lo general más delicado de las plantas, e) la alta frecuencia de presentar coloreados sus tallos, hojas y cálices de rojo.

Es posible que $H$. pugae se haya originado a partir de $H$. patens y el proceso evolutivo correspondiente haya involucrado un cambio significativo del sistema de protección de las plantas contra la acción desecadora del ambiente.

Por otro lado, no deja de ser notable el hecho de que en las 4 localidades conocidas de $H$. pugae, sus individuos conviven con los de $H$. patens, taxon distribuido desde el centro de Zacatecas a Hidalgo y centro de Puebla. Sin embargo, la convivencia de varias especies de Helianthemum es, al parecer, un fenómeno frecuente en el centro y norte de México, dada la coincidencia de ocupar hábitats semejantes. Así, por ejemplo, en el sitio próximo a Ibarra, Gto., se encontraron cohabitando $H$. glomeratum, $H$. patens y $H$. pugae; en cambio cerca de Laguna de Guadalupe, Gto. y de La Escondida, Gto., se registraron en vecindad inmediata $H$. glomeratum, $H$. patens, $H$. argenteum y $H$. pugae; a su vez en la proximidad de San Agustín, municipio de San Luis de la Paz, Gto., se colectaron $H$. glomeratum, $H$. coulteri, $H$. patens y $H$. argenteum.

El nombre de esta especie se dedica como homenaje a la Maestra Luz María Villarreal de Puga, organizadora y directora del Instituto de Botánica de la Universidad de Guadalajara, quien por largos años y con todo empeño ha colectado y estudiado la flora de Jalisco, a la vez que ha estado firme en la formación de numerosos botánicos.

\section{AGRADECIMIENTOS}

Se agradece a los Dres. Victoria Sosa, Fernando Chiang y J. Rzedowski la revisión del presente manuscrito y sus correspondientes sugestiones para mejorarlo, así como al Biól. Edmundo Saavedra por la elaboración de la ilustración. 
Calderón de Rzedowski: Helianthemum pugae Una Especie Nueva del Centro de México

\section{LITERATURA CITADA}

Daoud, H. S. \& R. L. Wilbur. 1965. A revision of North American species of Helianthemum (Cistaceae). Rhodora 67: 63-82; 201-216; 255-312. 